\title{
Correction to: Validating mouse-tracking: How design factors influence action dynamics in intertemporal decision making
}

\section{Martin Schoemann ${ }^{1} \cdot$ Malte Lüken $^{1} \cdot$ Tobias Grage $^{1} \cdot$ Pascal J. Kieslich $^{2} \cdot$ Stefan Scherbaum $^{1}$}

Published online: 13 November 2019

(C) The Psychonomic Society, Inc. 2019

\section{Correction to: Behav Res https://doi.org/10.3758/s13428-018-1179-4}

Fig. 1 from this article had been adapted from previous work for which the following reference was omitted:

Wulff, D. U., Haslbeck, J. M. B., Kieslich, P. J., Henninger, F., \& Schulte-Mecklenbeck, M. (2018, March). Advanced mouse- and handtracking analysis: Detecting and visualising clusters in movement trajectories. Paper presented at the 60 .
Tagung experimentell arbeitender Psychologen (Conference of Experimental Psychologists), Marburg, Germany. See also Wulff et al. (2019). Wulff, D. U., Haslbeck, J. M. B., Kieslich, P. J., Henninger, F., \& Schulte-Mecklenbeck, M. (2019). Detecting types in movement trajectories. In M. SchulteMecklenbeck, A. Kühberger, \& J. G. Johnson (Eds.), A Handbook of Process Tracing Methods (2nd ed.). New York: Routledge.

Publisher's note Springer Nature remains neutral with regard to jurisdictional claims in published maps and institutional affiliations.
The online version of the original article can be found at https://doi.org/ $10.3758 / \mathrm{s} 13428-018-1179-4$

Martin Schoemann

martin.schoemann@tu-dresden.de

1 Department of Psychology, Technische Universität Dresden, Dresden, Germany

2 Experimental Psychology, School of Social Sciences, University of Mannheim, Mannheim, Germany 